\title{
Plasma Gelsolin: Function, Prognostic Value, and Potential Therapeutic Use
}

\author{
Robert Bucki $^{\#, *}$, Ilya Levental ${ }^{\#}$, Alina Kulakowskall and Paul A. Janmey ${ }^{\#}$ \\ ${ }^{\#}$ University of Pennsylvania, Institute for Medicine and Engineering, 1010 Vagelos Research Laboratories, 3340 Smith \\ Walk, Philadelphia, PA, 19104, USA; "Department of Neurology, Medical University of Bialystok, 15-230 Bialystok, \\ Poland
}

\begin{abstract}
Gelsolin is a highly conserved, multifunctional actin-binding protein initially described in the cytosol of macrophages and subsequently identified in many vertebrate cells. A unique property of gelsolin is that in addition to its widely recognized function as a cytoplasmic regulator of actin organization, the same gene expresses a splice variant coding for a distinct isoform, plasma gelsolin, which is secreted into extracellular fluids. The secreted form of gelsolin has been implicated in a number of processes such as the extracellular actin scavenging system and the presentation of lysophosphatidic acid and other inflammatory mediators to their receptors, in addition to its function as a substrate for extracellular matrix-modulating enzymes. Consistent with these proposed functions, blood gelsolin levels decrease markedly in a variety of clinical conditions such as acute respiratory distress syndrome, sepsis, major trauma, prolonged hyperoxia, malaria, and liver injury. This correlation between blood gelsolin levels and critical clinical conditions suggests the potential utility of gelsolin as a prognostic marker as well as the possibility for therapeutic replenishment of gelsolin to alleviate the injurious cascades in these settings. This review summarizes current data supporting a role of plasma gelsolin in extracellular fluids and the potential for its use as a diagnostic marker or therapeutic treatment in several medical conditions.
\end{abstract}

Keywords: Plasma gelsolin, F-actin, LPA, LPS.

\section{PLASMA GELSOLIN - STRUCTURE AND REGU- LATION}

\section{A. Gelsolin Molecular and Subdomain Structure}

Gelsolin was discovered as an $83 \mathrm{kDa}$ single chain cytoplasmic actin-binding protein involved in the remodeling of cellular actin filaments associated with cell shape changes and movement [1]. Subsequent research revealed that gelsolin is nearly unique among mammalian cytosolic proteins in having a secreted isoform. Originally defined by its interactions with actin, this secretory form, now called plasma gelsolin, circulates in mammalian blood at concentrations of 200-300 $\mu \mathrm{g} / \mathrm{ml}[2-4]$. Human plasma gelsolin differs from the cytoplasmic isoform by an additional sequence of 24 amino acids, designated as the "plasma extension" signal that remains in the mature protein after cleavage of the peptide that directs plasma gelsolin to the secretory pathway into the endoplasmic reticulum, where plasma gelsolin folds and a disulfide bond is formed [4, 5]. Both cytoplasmic and plasma isoforms originate from the same $70 \mathrm{~kb}$ gene on chromosome 9 containing at least 14 exons, and alternative mRNA splicing and message processing leads to production of the two isoforms [6-8]. They share a common sequence of 730 residues comprising six structurally homologous domains (S1 through S6) of 120-130 amino acids, that appear to have evolved through a gene triplication process followed by an additional duplication [9, 10]. Hence, gelsolin can be

*Address correspondence to this author at the University of Pennsylvania, Institute for Medicine and Engineering, 1010 Vagelos Research Laboratories, 3340 Smith Walk, Philadelphia, PA, 19104, USA; Tel: 00-1-215 573 9787; Fax: 00-1-215 573 7227; E-mail: buckirob@mail.med.upenn.edu modeled as two domains (the N-terminal S1-S3 and the Cterminal S4-S6) halves separated by a 70 amino acid linker sequence, which is cleaved by many proteases [11-13]. Of the five cysteine (Cys) residues in the human gelsolin sequence, all are apparently in the free thiol form in human cytoplasmic gelsolin, while only three are free thiols in the human plasma form. A disulfide bond between Cys ${ }^{188}$ and $\mathrm{Cys}^{201}$ of the S2 domain contributes to the stability of that domain in the secreted form of the protein, suggesting that intracellular and extracellular gelsolin are somewhat structurally distinct [14].

\section{B. Gelsolin is a $\mathrm{Ca}^{2+}$-Dependent Actin Severing Protein}

The basic architecture of each homologous gelsolin domain (S1-S6) is $\mathrm{Ca}^{2+}$-independent and involves a central five-stranded mixed beat sheet sandwiched by two alpha helices, one longer than the other, running parallel and perpendicular to the sheets, respectively. These homologous domains fold together to adopt a compact globular shape [15], but each is associated with a distinct function, typically regulated by $\mathrm{Ca}^{2+}, \mathrm{pH}$, and acidic lipids such as polyphosphoinositides (PPIs) [6, 11, 16] Fig. (1). The S1 subunit binds actin monomers in absence of $\mathrm{Ca}^{2+}$, and the resulting complex caps the quickly growing ends of actin filaments, while $\mathrm{S} 2$ is responsible for binding F-actin filaments in a $\mathrm{Ca}^{2+}$-independent manner [5, 15]. The triplet of S4-S6 binds actin monomers at the same binding site on actin as $\mathrm{S} 1$ but only in a $\mathrm{Ca}^{2+}$-dependent manner [17], while S2-S6 can promote the nucleation of actin filaments. The S1-S3 fragment severs actin filaments in the absence of $\mathrm{Ca}^{2+}$ whereas whole plasma gelsolin severs them in a strictly $\mathrm{pH}$ or $\mathrm{Ca}^{2+}$ and PPI- 
dependent/regulated process [18]. A fully intact gelsolin moiety binds monomeric and filamentous actin very tightly, breaks the non-covalent bonds holding actin monomers together in the polymers, and following the severing reaction that involves a change in its conformation, remains bound as a cap to the rapid monomer-exchanging end of the filament (barbed end) [19, 20]. This reaction generates short actin filaments that cannot reassemble or grow at their barbed ends [21], until they are liberated by $\mathrm{PIP}_{2}$ or tropomyosin [31].

Both the cytoplasmic and plasma isoforms of gelsolin have at least three $\mathrm{Ca}^{2+}$-binding sites of nanomolar and micromolar affinity [17, 22], but gelsolin binds only two calcium ions in the presence of actin, and they bind cooperatively [23, 24] Fig. (1). A recent study reports a high resolution structure of full-length plasma gelsolin activated by calcium ions [11]. Previously available data regarding the structure of $\mathrm{Ca}^{2+}$-activated gelsolin has been provided by crystallographic investigation of the $\mathrm{Ca}^{2+}$-activated $\mathrm{C}$-terminal half of gelsolin in the presence and absence of actin $[25,26]$ and the $\mathrm{Ca}^{2+}$-activated $\mathrm{N}$-terminal half of gelsolin (S1-S3) bound to actin [27].

In the absence of $\mathrm{Ca}^{2+}$, the crystallographic structure of equine plasma gelsolin shows intimate interaction and packing of the domains to form a compact globular structure in which the putative actin-binding sequences are not exposed sufficiently to enable binding [15]. S1 is sandwiched between, and has extensive surface contact with, S2 and S3, which are connected over S1 by an extended stretch of 30 residues. The same organization is repeated with the $\mathrm{C}$ terminal triplet $\mathrm{S} 4-\mathrm{S} 6 . \mathrm{Ca}^{2+}$-binding releases the connections that join the $\mathrm{N}$ - and $\mathrm{C}$-terminal halves of gelsolin, enabling each half to bind actin relatively independently, although with more affinity in the $\mathrm{C}$-terminal half. These findings indicate that $\mathrm{Ca}^{2+}$ opens up gelsolin by inducing a conformational change in the C-terminal half [15]. The similarity be- tween the crystal structure of the $\mathrm{Ca}^{2+}$-bound C-terminal half of gelsolin in the presence and absence of actin suggests that calcium ions alone induce the actin-binding form of this half of gelsolin [26]. Upon $\mathrm{G}$-actin- and $\mathrm{Ca}^{2+}$-binding the structure of S4-S6 lacks interaction between S6 and S4 [28].

Low $\mathrm{pH}$ (5.5-6.0), which by itself does not induce conformational changes in S4-S6 beyond those elicited by calcium alone, significantly reduces the calcium ion requirement to initiate gelsolin severing activity $[29,30]$ suggesting that gelsolin can integrate these signals for functional output.

\section{Interaction of Gelsolin with Lipid Mediators: Phos- phoinositides, Lysophosphatidic Acid and Bacterial Wall Lipids}

A search of agents capable of removing gelsolin from the ends of actin filaments, thereby allowing actin polymerization triggered by signals regulating cell motility, lead to the finding that gelsolin-actin binding was reversed by the plasma membrane lipid phosphatidylinositol 4,5 bisphosphate $\left(\mathrm{PIP}_{2}\right)[31,32]$ and other polyphosphoinositides (PPIs). Removing calcium by chelation does not dissociate gelsolin from actin filament barbed ends. Rather, $\mathrm{PIP}_{2}$ and other PPIs, which are important signal transduction intermediates, effect this separation at the plasma membrane, leading to the hypothesis, well supported by experimental data, that a reciprocal relationship between calcium transients and membrane phosphoinositide synthesis and degradation regulate gelsolin and cellular actin remodeling responses [33,34]. Studies of proteolytic fragments [35] and recombinant gelsolin deletion mutants [36] identified two sequences of 10 to 20 amino acids responsible for the polyphosphoinositide-binding activity of intact gelsolin. Peptides based on sequences from either segment 1 (GSN135-142) [37] or segment 2 (GSN150169) [38] of gelsolin bind avidly to polyphosphoinositides and compete with the parent protein for binding PIP and PIP [38]. Both peptides are polyvalent cations with several hy-

Actin severing and capping,

$$
\begin{aligned}
& \mathrm{Ca}^{2+} \text {-independent } \\
& \text { PIP }_{2} \text {-dependent }
\end{aligned}
$$

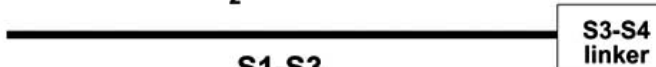

S1-S3
Actin binding and capping,

$$
\begin{aligned}
& \mathrm{Ca}^{2+} \text {-dependent } \\
& \text { PIP }_{2} \text {-independent }
\end{aligned}
$$

\section{S4-S6}

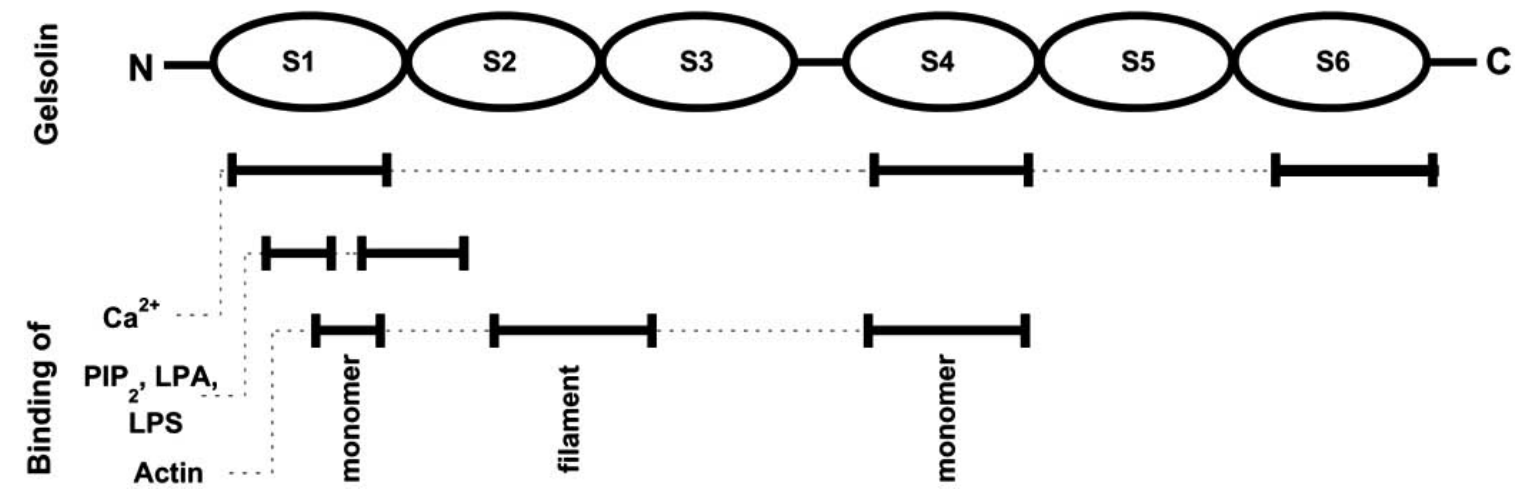

Fig. (1). Functional sites in gelsolin. Gelsolin has been considered as two domain triplets of the N- (S1-S3) and C-terminal (S4-S6) halves separated by a 70 amino acid linker sequence. Gelsolin binds G-actin, nucleates actin filaments growth, severs actin filaments, and caps their fast-growing ends. 
drophobic residues. Their binding to PPI's is not exclusively electrostatic since it is much stronger than that of similar peptides that have larger positive charges [38]. The gelsolinderived sequence (GSN160-169) (QRLFQVKGRR) competes well with intact gelsolin for binding PPIs, and when added to permeabilized cells exerts effects consistent with a potent inhibition of the production or presentation of PPIs, which uncap actin filament ends and desequester actin monomers required for the actin assembly reaction at the cytoskeleton/membrane interface $[39,40]$. As $\mathrm{PIP}_{2}$ inhibits the severing activity of cytosolic and plasma gelsolin in the same way, it may be concluded that $\mathrm{PIP}_{2}$-gelsolin binding is unaffected by the plasma extension sequence of gelsolin.

PPIs were the only intracellular agents, among many tested, that reversed gelsolin's actin-binding function. Meerschaert et al. [41] reported similar regulation of gelsolin by lysophosphatidic acid (LPA), a bioactive lipid thought to exert its function primarily as an extracellular molecule, produced by the action of phospholipase $\mathrm{A}_{2}$ [42]. LPA and $\mathrm{PIP}_{2}$ have in common a phosphomonoester on the hydrophilic headgroup, a moiety rarely found in phospholipids. This finding, and the complex effect (detailed below) that gelsolin has on stimulation of cells and tissues by LPA [43, 44], lead to the hypothesis that binding of LPA to extracellular gelsolin during inflammation has deleterious effects either because LPA inhibits gelsolin's actin-scavenging function or because gelsolin acts as a carrier/presenter for LPA [43]. The same studies that identified LPA as a ligand for gelsolin did not report similar effects for another major bioactive lipid bearing a phosphomonoester, sphingosine 1-phosphate (S1P) [41], but these studies, which did show some effect of S1P on gelsolin, may have been affected by the very low solubility of S1P in aqueous solvents [45]. Gelsolin binds LPA with an affinity similar to that of the G protein-coupled LPA receptors encoded by endothelial differentiation genes 2, 4, and 7 (Edg-2, -4 , and -7 receptors; $\left.K_{d}=6 \mathrm{nM}\right)$, and greater than that of albumin $\left(\mathrm{K}_{\mathrm{d}}=360 \mathrm{nM}\right)$ another potential LPA carrier in the blood. In the presence of gelsolin, the cellular effects of LPA depend on the abundance of gelsolin compared to LPA. At gelsolin concentrations of $10 \%$ or less of that in plasma, typical of concentrations in fluids of injured tissues, purified and recombinant gelsolin augments LPA stimulation of nuclear signals and protein synthesis in rat cardiac myocytes (RCMs) that express Edg-2 and -4 receptors. Conversely, at concentrations of $20 \%$ or more of that in plasma, gelsolin suppresses LPA stimulation of RCMs [43]. The cellular effects of LPA were found to be affected by $\mathrm{PIP}_{2}$ and peptides constituting the two $\mathrm{PIP}_{2}$-binding domains of gelsolin. These agents inhibit the gelsolin binding and cellular delivery of LPA suggesting competition between LPA and PIP $_{2}$ for the same gelsolin binding sites [43].

While there is no apparent relationship between the function or metabolism of bacterial LPS and eukaryotic cell LPA or $\mathrm{PIP}_{2}$, these lipids share two unusual and essential structural characteristics. The active site of each molecule contains a phosphomonoester emanating from a carbohydrate base, glycerol in the case of LPA and a sugar ring for LPS and $\mathrm{PIP}_{2}$. These phosphomonoester moieties, which are present in few other lipids, present possibilities for electrostatic and hydrogen-binding interactions that stabilize both lipidprotein and lipid-lipid complexes [46]. None of these lipids forms lamellar phases by themselves [47], and binding to gelsolin appears to be strongest when the lipid is monomeric (for LPA) or in micelles or putative lipid clusters within bilayers (for $\mathrm{PIP}_{2}$ ) $[16,41,48]$. The structural similarities between $\mathrm{PIP}_{2} / \mathrm{LPA}$ and lipopolysaccharides (LPS) lead to the hypothesis that gelsolin may bind these lipids at the same site. The first experimental evidence for the hypothesis that gelsolin can selectively interact with bacterial wall products (LPS in gram-negative bacteria and lipoteichoic acid (LTA) in gram-positive) was the demonstration that the rhodamineB-labeled peptide based on gelsolin's $\mathrm{PIP}_{2}$-binding sequence (PBP10) has antibacterial activity against gram-negative and gram-positive bacteria [49], likely resulting from the interaction of PBP10 with the negatively charged bacterial wall lipids. Subsequent studies with PBP10 and recombinant human plasma gelsolin confirmed that PBP10 binds both LPS [50] and LTA [51]. Similarly, purified plasma gelsolin binds LPS extracted from various bacteria such as Escherichia coli, Salmonella enteritidies, Pseudomonas aerugnosa or Klebsiella pneumonie [50, 52]. Solid phase binding assays, fluorescence measurements, and functional (actin depolymerizing) assays also showed that gelsolin binds more tightly to LPS than it does to its other lipid ligands, PIP $_{2}$ and LPA [50]. Gelsolin also competes with LPS-binding protein (LBP-LPS $\mathrm{K}_{\mathrm{d}} \sim 2 \times 10^{-9} \mathrm{M}$ ), a high affinity carrier for LPS that, in cooperation with CD14 and MD2 proteins, is involved in LPS presentation to membrane-bound toll-like receptors (TLRs) [50, 53]. On the other hand gelsolin by itself has no effect on bacterial growth, or ability to act synergistically with natural antibacterial peptides such as LL37 (unpublished observation) in a killing assay against Pseudomonas aeruginosa (PAO1).

Binding between LPS and gelsolin has several functional consequences. Gelsolin that is bound to LPS is inhibited in its actin binding activity with a resulting inhibition of the actin depolymerizing activity of blood serum [50] Fig. (2). Also, due to direct binding, gelsolin interferes with LPSmediated thrombin inhibition [54]. Similarly, the effects of LPS on cellular functions, including cytoskeletal actin remodeling, and collagen-induced platelet activation by pathways independent of toll-like receptors (TLR) are neutralized by gelsolin and by a peptide based on gelsolin's $\mathrm{PIP}_{2}$-binding residues [50]. Additionally, TLR-dependent NF- $\kappa B$ nuclear translocation in astrocytes appears to be blocked by gelsolin Fig. (2). All of this evidence suggests that the inflammatory and coagulatory effects of LPS in vivo may be mediated or inhibited by interaction with plasma gelsolin, although further study has revealed that the gelsolin effect on LPSmediated cell activation has some cellular specificity, as indicated by a lack of gelsolin effect on LPS-induced monocytic cell (THP-1) activation [52]. The root of these complex gelsolin effects may lie in the complexity of the inflammatory reaction, which involves cross-talk between numerous immunocompetent cells, which is in turn mediated by many different lipid effectors. It is possible that in addition to its ability to sequester LPS from its TLRs, gelsolin may also modulate the effects of other lipid mediators involved in inflammatory process synthesized upon LPS activation, leading to complex and unexpected effects of gelsolin on inflammatory cell activation and interaction Fig. (2). 


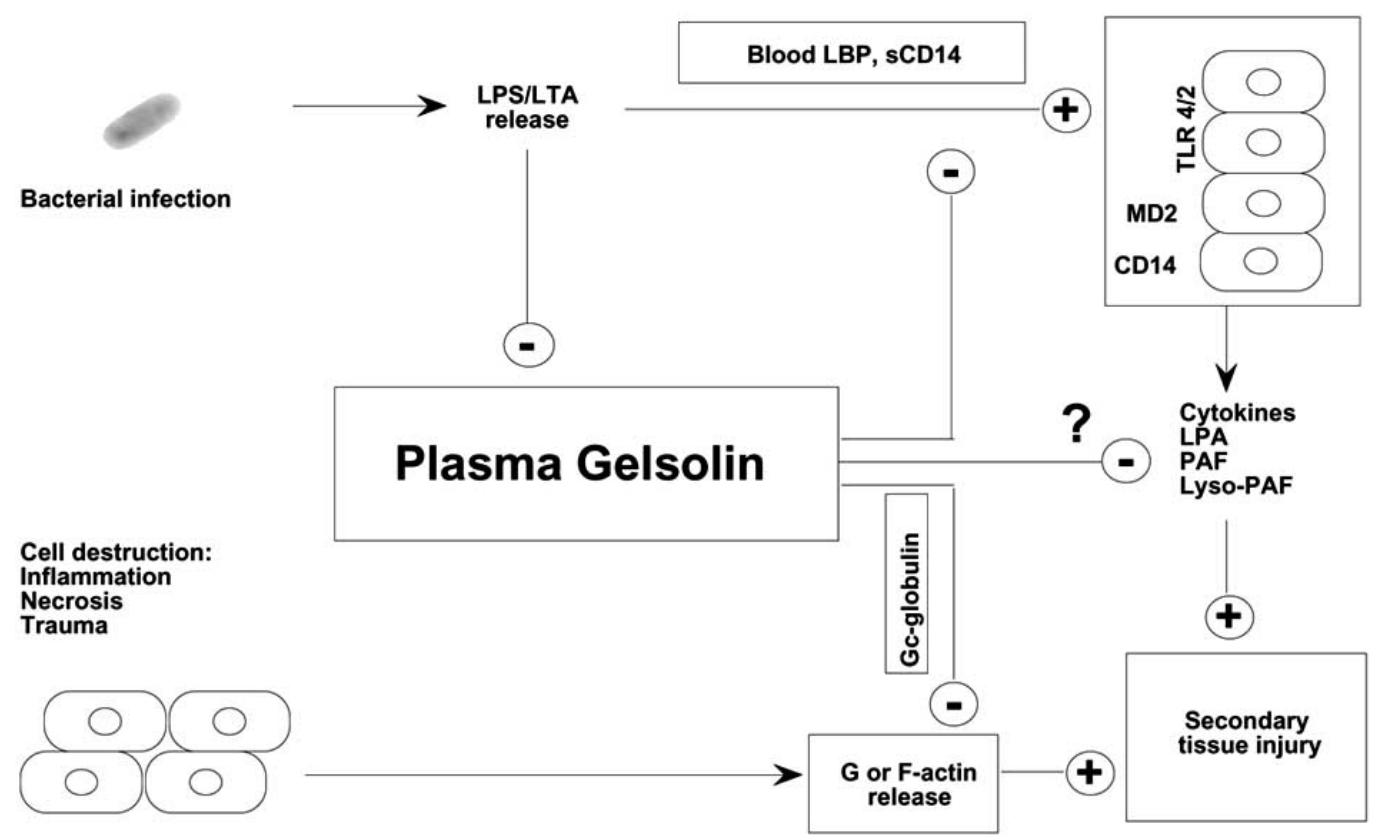

Fig. (2). Placement of gelsolin in a mechanism of secondary tissue injury as an F-actin scavenger and buffer of inflammatory cytokines. Primary injury, resulting in actin exposure, might predispose, through the toxicity of actin, the development of secondary tissue injury. Gelsolin is involved in actin clearance based on its ability to bind and disassemble actin filaments. Gelsolin my also be involved in regulation of inflammatory processes through interaction with LPA, PAF and LPS.

\section{Gelsolin Interacts with Plasma ATP in a $\mathrm{Ca}^{2+}$-Depen- dent Manner}

Despite the low physiological concentration of ATP in plasma $(\sim 550 \mathrm{nM})$ compared to its intracellular concentration of 3-10 mM [55], plasma ATP exerts important effects through binding to its plasma membrane purinergic receptors. Most cells co-express both P1 and P2 purinergic receptor subtypes, and these subtypes exert different, and sometimes opposite effects on cell function, which results in the ability of ATP to induce dual effects on the same cell type [56]. For example, at low micromolar concentration, ATP can promote neutrophil accumulation via $\mathrm{P} 2 \mathrm{Y} 2$ receptor activation, either directly by acting as a chemoattractant, or indirectly by facilitating leukotriene B4 (LTB4) production. On the contrary, upon arriving at inflamed sites where ATP levels are highest, neutrophil migration can be inhibited by ATP allowing the neutrophils to exert their bactericidal functions at sites of injury [56, 57]. Signaling by purinergic receptors depends on a wide variety of factors including the varying levels of extracellular ATP, the activity of ectoenzymes involved in ATP extracellular metabolism, and factors that bind and sequester ATP from its receptors [56]. One such binding protein is gelsolin, which binds ATP with a $\mathrm{K}_{\mathrm{d}}$ of $2.4 \mu \mathrm{M}$ in a solution containing $2 \mathrm{mM} \mathrm{MgCl}_{2}$ [58], but micromolar free $\mathrm{Ca}^{2+}$ concentrations inhibit ATP binding $\left(\mathrm{K}_{\mathrm{d}}\right.$ $=400 \mu \mathrm{M})$ for $\mathrm{Ca}^{2+}$-activated gelsolin [23]. ATP was found to decrease the rate of association of gelsolin with actin and ATP accounts for $84 \%$ of the nucleotide in G-actin bound to the plasma gelsolin complex (2:1) in vitro [59]. Furthermore, $\mathrm{Ca}^{2+}$ rapidly reverses the binding between preformed nucleotide and gelsolin, suggesting that $\mathrm{Ca}^{2+}$ binding to gelsolin leads to a conformational change that disrupts a nucleotide binding fold in the protein molecule [58]. These conclusions are consistent with structural studies showing that soaking calcium-free gelsolin crystals in ATP-containing media results in ATP occupying a site that spans the two pseudosymmetrical halves of the protein. These structures suggest that the gamma-phosphate of ATP participates in several high affinity charge-based interactions, consistent with the preference of gelsolin for ATP as a binding partner over ADP [60]. Similarities between the interactions of gelsolin with ATP and $\mathrm{PIP}_{2}$ are evident from their overlapping binding sites and from the fact that both molecules bind with higher affinity in the absence of calcium ions [60]. A biological function has not yet been ascribed to gelsolin-ATP binding in extracellular compartments, and one may be unlikely since calcium ions are usually present at $\mathrm{mM}$ concentration in these environments.

\section{FUNCTIONS OF PLASMA GELSOLIN}

\section{A. The Function of Gelsolin in Extracellular Fluids is Largely Unknown}

Gelsolin is not modified post-translationally by glycosylation, and in contrast to most plasma proteins, liver is not the site of gelsolin synthesis. Instead skeletal, cardiac and smooth muscle are believed to be the major sources of plasma gelsolin in the bloodstream [61], devoting $0.5-3 \%$ of their biosynthetic activity to produce this protein [61, 62]. Gelsolin appears to distribute throughout extracellular fluids and has a residence time in plasma typical for plasma proteins such as albumin [63]; it is not an acute phase reactant and little information exists concerning the regulation of its production or secretion. In addition to blood, gelsolin was also found to be present in airway surface fluid (ASF) as the secretion product of IL-4-activated lung epithelial cells [64], lymph [65] and cerebrospinal fluid (CSF), where neurons appear to be a significant source $[66,67]$. However, there has yet to be a study where the presence of plasma gelsolin was 
tested in extracellular space using an antibody specific only to its secreted isoform. This fact suggests the possibility that cytoplasmic gelsolin released from damaged or dying cells interferes with measurements of the concentration and activity of plasma gelsolin $[68,69]$. To address this issue, some studies evaluated the presence of gelsolin in blood parallel to the presence of actin as a measure of cell damage [64].

To determine the critical functions of gelsolin in vertebrates, transgenic gelsolin-null mice of mixed strain backgrounds (C57/BL/6 and 129/sV) were generated [70, 71]. The viability and normal fertility of those knock-outs was surprising, given the high level of gelsolin expression in many adult murine tissues [61]. However, despite normal embryonic development and longevity, physiological dysfunctions in hemostasis (prolonged bleeding times, decreased platelet shape changes), inflammatory reaction (delayed neutrophil migration in vivo into peritoneal exudates), and possibly tissue remodeling (excessive actin stress fibers, slow migration, increased contractility, defective neurite retraction) were observed in these animals [70-72]. Gelsolinnull mice are also deficient in the plasma isoform of gelsolin, and blood obtained from those animals shows no detectable F-actin severing activity. Based on this observation, it was proposed that vitamin D-binding protein (which binds Gactin with high affinity) is present in serum at a level sufficient to protect these mice from actin liberated to the circulation from injured tissue. Observations with gelsolin-null mice indicate that some proteins with functional similarity could compensate for a complete lack of gelsolin expression, or that gelsolin's function(s) can be performed by redundant mechanism(s). However, this compensation must depend on the animals genetic profiles, since gelsolin-null mice in a pure strain background are non-viable at the perinatal stage, while only cross-breeds survive [20,73]. The lack of both the cytoplasmic and extracellular gelsolin isoforms in gelsolin-null mice makes straightforward determination of the importance of each individual isoform impossible, since the function of circulating gelsolin during inflammation may be confounded by the compromised neutrophil migration, dysfunction of macrophage phagocytosis and fibroblast defective chemotaxis and wound healing that would result from a lack of cytoplasmic gelsolin [74-77]. Currently, there has been no evaluation of the response of gelsolin-null mice to inflammatory challenge, but the relationship between intra and extracellular gelsolin function probably reflects a complex balance between the multiple effectors of this protein, which may be affected to different extents when expression of gelsolin is disrupted.

\section{B. Gelsolin Acts as An Actin-Scavenging Protein}

Since actin represents $10 \%$ of human body protein, comprising about $25 \%$ of muscle and from 2 to $20 \%$ of nonmuscle tissues [78, 79], the discovery that plasma gelsolin and the vitamin D-binding protein Gc-globulin were actinbinding proteins led to the hypothesis of an extracellular actin scavenger system. This system is putatively designed to remove actin released from damaged cells $[63,80]$ in order to prevent increases in blood viscosity and possible toxicity of insoluble F-actin filaments. When G-actin is released from damaged cells, its polymerization is theromdynomically favored in the extracellular space leading to filamen- tous actin formation [81]. The actin scavenger hypothesis was supported by evidence that extracellular actin was toxic to rats [81] and actin-containing sera were toxic to endothelial cells [82], and that actin-binding proteins inhibited the toxic effects. Extracellular actin, by promoting alpha hemolysin (HlyA) production, may also enhance the severity of Escherichia coli infections, suggesting F-actin involvement in pathogenic mechanisms at infection sites [83]. The high viscosity of actin filaments, the inhibitory effect of actin on fibrinolysis [84], and the fact that actin binds adenine nucleotides that could activate purinergic receptors [85] were mechanisms invoked for possible secondary tissue damage. This hypothesis led to the conclusion that primary injury, resulting in actin exposure, might predispose, through the toxicity of actin, the development of secondary tissue injury.

Gelsolin can potentially serve a similar role in all extracellular compartments where it is present by scavenging and buffering actin present in these compartments Fig. (2). Mechanisms for F-actin and G-actin elimination after its release to extracellular compartments are different; G-actin removal is accomplished by Kupffer cells, whereas F-actin removal occurs in hepatic endothelial cells [86]. Therefore, gelsolin may aid in the elimination of actin through its Factin depolymerization in concert with the liver's Kupffer cells' G-actin removal function. In support of this hypothesis, investigators documented reductions of plasma gelsolin level in a variety of human and animal injury states, and in some cases detected circulating gelsolin-actin complexes [3, $87,88]$. A recent study in which the appearance of circulating actin was investigated in mice subjected to LPSchallenge or peritonitis (CPL) showed that actin was detectable in blood as early as 6 hours after LPS injection, and its amount progressively increased to $250-500 \mu \mathrm{g} / \mathrm{ml}$. In mice receiving injected gelsolin, the amount of circulating actin was similar to controls, but ultracentrifugation revealed that the actin in gelsolin-treated mice was mostly in its soluble form [52]. This evidence strongly suggests a role for gelsolin's actin scavenging and clearance activity; however, little research has been done to assess if gelsolin has other physiologic functions in addition to the hypothesized actin scavenging [89].

\section{Gelsolin is a Substrate for Matrix Metalloproteinases}

Matrix metalloproteinases (MMPs) are a family of zinccontaining endopeptidases that proteolyze extracellular matrix components such as collagens, proteoglycans, fibronectin, laminin, and elastin as well as a variety of functional proteins including fibrinogen and interleukins [90-92]. Recently, using a "degradomics" method that identifies protease substrates in a complex protein mixture (by incubation of the protein mixture with the protease, followed by $2 \mathrm{D}$ gel electrophoresis to identify the component fragments), gelsolin was found as one of MMP-14's blood plasma substrates [93]. In addition to MMP-14, gelsolin is cleaved most efficiently by MMP-3 followed in order of efficiency by MMP-2, MMP-1, MMP-14, and MMP-9 [94]. MMP-3 generates two gelsolin fragments of 43-48 kDa. Further analysis identified the MMP-3 cleavage sites in plasma gelsolin by separation of the cleaved fragments combined with peptide mass mapping and sequencing of the amino acids. Upon MMP-3 digestion, plasma gelsolin was found to be cleaved 
at $\mathrm{Asn}^{416}-\mathrm{Val}^{417}, \mathrm{Ser}^{51}-\mathrm{Met}^{52}$, and $\mathrm{Ala}^{435}-\mathrm{Gln}^{436}$. These cleavage sites differ from those described for caspase-3, which cleaves intracellular gelsolin between $\mathrm{Asp}^{352}-\mathrm{Gly}^{353}$ generating an N-terminal fragment that contributes to morphological changes during apoptosis $[12,95]$.

Functional analysis revealed that proteolytic cleavage by MMP-3 resulted in considerable loss of gelsolin's actin filament-depolymerizing activity, suggesting that MMPs weaken the extracellular actin-scavenging system and may therefore be involved in pathological conditions induced by unremoved extracellular actin [93, 94]. The gelsolin fragments generated by caspase- 3 digestion retain the activity ascribed to individual segments [96] and based on the structural interpretation of S1-S3 association with actin, it was proposed that this interaction drives the calcium-independent activation of gelsolin's isolated N-terminal fragment during apoptosis, and that a similar mechanism operates to activate native gelsolin at micromolar levels of calcium [27]. Another type of MMP, the metalloprotease MT1, that also cleaves gelsolin may represent an important therapeutic target for treatment of Finnish type amyloidosis (FAF) characterized by corneal lattice dystrophy and progressive cranial and peripheral neuropathy $[67,97,98]$. It was recently found that degradation of a mutant plasma gelsolin (D187Y/N, FAFmutant $\mathrm{Asp}^{187} \rightarrow \mathrm{Asn} / \mathrm{Tyr}$ ) by furin yields a $68-\mathrm{kDa}$ carboxylterminal fragment of gelsolin (GSN-c68), identified as the source of the FAF amyloid that accumulates as deposits in the extracellular matrix after metalloprotease MT1-mediated degradation of GSN-c68 to the 8 and $5 \mathrm{kDa}$ amyloidogenic peptides [99]. This finding has led to the hypothesis that inhibition of metalloprotease MT1 may prevent accumulation of amyloidogenic peptides which could be therapeutic for treatment of FAF neuropathies.

\section{CONCENTRATION OF BLOOD PLASMA GEL- SOLIN IN CLINICAL SETTINGS}

\section{A. Significant Depletion of Plasma Gelsolin and Secon- dary Tissue Injury}

Blood gelsolin levels were found to decrease after parenchymal tissue damage in a variety of conditions requiring urgent medical attention, mostly because of secondary complications that developed in the time frame of hours after the primary injuries. These conditions included acute respiratory distress syndrome (ARDS), acute lung injury (ALI) and multi-organ dysfunction syndromes (MODS) [100]. The development of ARDS following extensive primary injuries fits the hypothesis that actin released in excess of gelsolin's scavenger capacity would distribute to multiple organ systems, and specifically the lung because of its size and rich blood supply, possibly leading to the characteristic inflammatory responses of ARDS. Plasma gelsolin levels were, on average, $30 \%$ of their normal values in ARDS cases [3], and other studies reported that plasma gelsolin was reduced in sepsis, myocardial infarction, hepatitis, myonecrosis [101] and trauma [102, 103]. Additional studies have documented a negative correlation between decreased gelsolin and both aminotransferase and bilirubin levels in acute hepatitis [101]. In one study of trauma patients, lower plasma gelsolin levels were found to be associated with poor outcomes [102] and correlated with negative clinical outcomes in critically ill surgical patients in another study [104]. Furthermore, bone marrow transplant patients with lower plasma gelsolin levels were more likely to develop respiratory complications and death [105]. These data strongly suggest that plasma gelsolin depletion precedes, and therefore might predict, secondary inflammation and tissue injury, and that hypogelsolinemia (to less than $\sim 25 \%$ of it normal level) can be an indicator of critical care complications.

\section{B. Mechanisms for Plasma Gelsolin Depletion, and Mechanisms Of Deleterious Consequences, are Unknown}

The molecular mechanisms of blood plasma gelsolin depletion, as well as the mechanisms for the resulting critical consequences, are not known. Hypotheses include gelsolin accumulation at injury sites as a result of its interaction with insoluble F-actin that associates with cell membranes [106, $107,108]$ as well as gelsolin clearance by the reticuloendothelial system [109] when bound to G-actin or inflammatory mediators. The fact that gelsolin depletion was not observed in LPS-challenged $\mathrm{C} 3 \mathrm{H} / \mathrm{HeJ}$ mice carrying a mutation in TLR4 that renders the mice resistant to LPS-induced inflammation [52] suggests that gelsolin binding to this lipidic mediator does not itself cause blood clearance, but an explanation for clearance based on gelsolin's interaction with plasma actin also lacks experimental proof.

\section{Increase in Plasma Gelsolin Concentration in FAF and Rhabdomyolysis}

In contrast to low gelsolin levels in inflammatory settings, a surprising increase in blood plasma gelsolin level was reported in subjects suffering from familial amyloidosis of the Finnish type (FAF) [110] and rhabdomyolysis, which is characterized by acute destruction of skeletal muscle [111]. The proposed mechanisms to explain this tendency were induced synthesis secondary to actin release or liberation from gelsolin-actin complexes. Despite acute severe muscle damage, a slight increase in serum gelsolin was observed, with a peak that did not correlate temporally with the peak concentrations of serum creatine kinase $(\mathrm{CK})$, an indicator of muscle cell damage, and therefore presumably release of actin. Although this rhabdomyolysis study provides interesting evidence contrary to the previously observed decreases in plasma gelsolin with acute injury, the limited number of subjects included in the study must be mentioned as a possible source of variation.

\section{PLASMA GELSOLIN AS A THERAPEUTIC TREA- TMENT IN MEDICAL CONDITIONS}

\section{A. Basis for Hypothesis of Therapeutic Value of Gelsolin}

The potential of gelsolin as a treatment has been proposed on the basis of two observations: (1) the ability of this protein to disassemble F-actin in extracellular environments; and (2) the observed depletion of plasma gelsolin in subjects under urgent medical conditions associated with several different types of tissue injury. Gelsolin has been suggested to prevent or counteract the pathological consequences of $\mathrm{F}$ actin present in extracellular spaces such as the airway surface fluid or blood, that may act as a noncompetitive inhibitor of plasmin [84], modulator of fibrin-fibrin interaction 
during clot formation [112], and source material for pulmonary microthrombi [81]. In addition to possible therapeutic effects of F-actin clearance, gelsolin repletion by injection of recombinant protein may prevent critical care complications caused by its observed depletion.

\section{B. Gelsolin Depolymerizes F-Actin in Cystic Fibrosis Sputum}

The first proposed application of using plasma gelsolin as a therapeutic agent was directed to decreasing the abnormal viscoelasticity of cystic fibrosis (CF) sputum (caused by DNA and F-actin accumulation) in order to facilitate the clearance of the sputum by the lungs' mucocilliary mechanism. DNA and F-actin, released mostly from neutrophil remnants present at sites of inflammation, are fibrous polymers that can independently form viscoelastic networks, and their incorporation into the mucus network of the airway fluid severely alters the rheological properties of sputum. The rheologic effects of both actin and DNA result not from the interpenetration of single DNA or F-actin filaments into the mucopolysaccharide networks, as was first envisaged. Rather, actin and DNA in CF sputum are found tightly intertwined in larger bundles that dissociate when either of the two polymers is disassembled. Depolymerization of DNA and F-actin polymers restores the rheology of sputum to more nearly normal levels [113, 114], likely leading to enhanced clearance. Those observations provided a scientific basis for using plasma gelsolin as a therapeutic mucolytic agent in the treatment of symptoms resulting from $\mathrm{CF}$ lung disease, and use of aerosolized gelsolin underwent phase II clinical trials. This trial, in which a small number of patients $(n=16)$ and controls received three administrations of gelsolin, and in which the volume exhaled during the first second of a forced expiratory maneuver $\left(\mathrm{FEV}_{1}\right)$ was the measured response, showed no significant improvement of lung expiratory function [115]. However, the clinical testing did show that gelsolin was well tolerated when delivered by aerosol in humans. Also, because acute improvement in $\mathrm{FEV}_{1}$ was the only measured parameter, other potentially beneficial effects of gelsolin in CF such as effects on inflammatory responses and bacterial growth might be still considered [50, 116]. Indeed, the mucolytic DNase (Pulmozyme), used in $49 \%$ of CF patients in the US produced only a $5.6 \%$ increase in $\mathrm{FEV}_{1}$, but a $34 \%$ decrease in infections in a multi-trial analysis $[117,118]$. Similar results were obtained in a study of young children with early disease who responded to DNase with a slight or insignificant $3 \%$ increase ( $<10 \%$ after 2 years) in $\mathrm{FEV}_{1}$, but a substantially greater reduction in infections requiring intravenous antibiotics [115].

\section{Possible Anti-Inflammatory Functions of GSN in CF Lung}

This discrepancy between the expiratory volume effect of DNase and its substantially greater inhibition of bacterial infection is unexplained in the literature but consistent with the hypothesis that fluidizing the sputum by depolymerizing DNA/F-actin is beneficial for reasons besides increasing lung volume through mucous clearing. In vitro studies to investigate the cause of this unknown beneficial effect showed that in addition to modulation of the viscoelastic properties of CF sputum, disassembly of DNA/F-actin bundles liberated endogenous antibacterial molecules such as beta-defensins, LL37 peptide or lysozyme trapped in the CF sputum network and restored their bacterial killing activity [119-121]. It is possible that gelsolin-mediated depolymerization of F-actin induces the release of native antibacterial peptides from DNA/F-actin bundles.

Gelsolin may also contribute to antibacterial activity by binding released bacterial wall molecules such as LPS [50] expressed by Pseudomonas aeruginosa [122] and LTA from Gram positive bacteria [51]. Although endotoxin-like effects of LPS released from Pseudomonas aeruginosa do not appear to be a dominant feature of the pathology of CF [123], the presence of LPS released from lysed bacteria in the airway fluid may still contribute to disease symptoms by inactivation of antimicrobial peptides [51]. The same electrostatic/hydrophobic interactions that make LPS or LTA the likely targets of cationic antimicrobial peptides also mean that these peptides will bind and complex with LPS or LTA released from bacteria, possibly with even greater affinity [120, 124]. Cationic antimicrobial peptides (CAPs), including LL37, have been shown to inhibit the eukaryotic cellular effects of LPS, however antibacterial peptides in tight complexes with free LPS may be incapable of interacting with bacteria. Gelsolin, or gelsolin-derived peptides, may be able to compete with antimicrobial peptides to bind LPS/LTA and prevent the loss of CAPs' antimicrobial activity [120].

In concert with the liberation of antibacterials, gelsolinmediated disassembly of DNA/F-actin may prevent the formation of biofilms, since these molecules have been shown to induce the expression of Pseudomonas aeruginosa alginate [116]. Although there are multiple possible effects of neutrophils on Pseudomonas aeruginosa biofilm production, extracts of neutrophils containing actin are $94 \%$ as potent as intact neutrophils on enhancement of biofilm production by Pseudomonas aeruginosa. Of three neutrophil extract fractions tested, granular proteins and DNA had little to no effect on biofilm production, whereas purified F-actin had a strong stimulating effect, while depleting actin from whole neutrophil lysates diminished this stimulating activity [116]. These findings suggest the possibility that the dissolution of Factin/DNA bundles by depolymerization of actin with gelsolin may reverse the strong effect of actin to stimulate Pseudomonas aeruginosa biofilm production in CF lung and account for the unexplained inhibition of bacterial infections by DNase.

\section{Gelsolin Repletion in Critical Medical Conditions}

In addition to its possible efficacy in the treatment of symptoms from $\mathrm{CF}$, a broader therapeutic application of gelsolin was proposed based on the correlation of the decrease in blood plasma gelsolin and poor clinical income in several different, usually critical, medical conditions occurring in relation to cell/tissue injury. Hypothetically, in those conditions, injection of recombinant plasma gelsolin in an optimal time interval will prevent secondary tissue injury, which may greatly decrease mortality, ventilator hours, and length of hospital stay. To test this hypothesis, studies to determine whether repletion of plasma gelsolin can provide benefits 
were recently conducted in animal models. The first study used a murine hyperoxic lung injury model to demonstrate depression of plasma gelsolin in mice subjected to hyperoxia, correlating with development of lung injuries [125]. Furthermore, it was found that treatment of mice with exogenous plasma gelsolin significantly blunted neutrophil recruitment to the lungs [126]. Another study showed that plasma gelsolin was able to attenuate vascular permeability associated with burn injury in rats subjected to a $40 \%$ fullthickness burn, an injury that resulted in $70-80 \%$ drops in plasma gelsolin persisting up to 72 hours [127]. The possible protective role of gelsolin in preventing leakage into the lung is supported by the observation that gelsolin null mice have significantly higher airway protein concentrations compared to littermate heterozygote controls, and that they accumulate much more protein after ischemic injury [44]. In addition to these reports, recent studies using animal models of sepsis indicated that gelsolin injection $(8 \mathrm{mg} /$ mouse) prevented death after LPS-challenge and enhanced survival in mice subjected to peritonitis induced by cecal ligation and puncture (CLP) [52]. The results of these experiments support the hypothesis that plasma gelsolin might be a promising treatment in clinical settings in which primary injury results in cell death followed by secondary complications such as ARDS [128].

A proposed mechanism for plasma GSN's protective effects considers its ability to act as a buffering agent for cellactivating mediators. Actin released from damaged cells to the extracellular environment at a site of injury or infection may induce local accumulation of gelsolin leading to a decrease in circulating plasma gelsolin levels and reduction of its inflammatory mediator buffering capacity [129]. In accordance with this proposed mechanism, plasma gelsolin inhibits the effects of pro-inflammatory agonists and inflammatory mediators, such as endotoxin (LPS) [50], lysophosphatidic acid (LPA) [130], platelet-activating factor (PAF) [129] and diadenosine-5', 5"-P1, P3-triphosphate (Ap3A) [131], generated during primary injuries. However, no direct in vivo evidence has been observed in support of this hypothesis. Recombinant plasma gelsolin in the presence of albumin was found to function as an inhibitor of LPAinduced P-selectin presentation on isolated human platelets. Plasma gelsolin at physiologically relevant concentrations also inhibited PAF-mediated P-selectin expression by more than $50 \%$, in addition to a concentration-dependent inhibition of PAF-induced superoxide anion production in purified human neutrophils, a process associated with acute lung injury $[132,133]$. However, in this experimental setting, the inhibitory effect of gelsolin was not observed when TRAP or fMLP were used as agonists instead of PAF/LPA [129]. In contrast to LPA, PAF does not circulate as a normal constituent of blood in healthy subjects both because of strict regulation of its production and its rapid hydrolysis in plasma by LDL-associated PAF-acetylhydrolase (PAF-AH). Despite this strict regulation, PAF was detected in bronchoalveolar lavage (BAL) of patients with ARDS [134] and plasma obtained from septic and trauma patients at concentrations reaching $60 \mathrm{nM}$ [135-137]. Currently it is unknown if in addition to PAF, plasma gelsolin is able to antagonize the cellular effects of PAF degradation products such as lyso-PAF, lysophosphatidylcholine (lyso-PC), or short chain fatty acids generated upon PAF-AH activity, all of which induce deleterious effects on the vessel wall and immunocompetent cell activation [138-140].

In addition to the inhibitory effects of GSN on inflammatory mediators, the functionality of GSN is also affected when it is bound to various pro-inflammatory mediators. LPA and LPS, but not PAF, interfere with plasma gelsolin's severing activity, whereas PAF but not LPA increased plasma gelsolin-mediated nucleation of actin polymerization [129]. Although, it is unlikely that the PAF nucleating effect has physiological relevance, it is likely that the inhibition of plasma gelsolin severing activity due to LTA or LPS binding, combined with the observed decreases in gelsolin concentration, may enhance the toxicity of F-actin at sites of bacterial infection.

The observations described above show that plasma GSN interferes with LPS, PAF, and LPA-induced cellular activation in vitro, suggesting a mechanism for the protective role of plasma gelsolin in vivo [50, 129]. However, optimism for using plasma gelsolin as a treatment in critical clinical conditions is moderated by a number of interesting, but still unanswered, questions regarding the dosage, administration, pharmacology and pharmacokinetics of it recombinant form, the possible toxicity of hypergelsolinemia, and the still not defined mechanism of in vivo action [89, 128]. Additionally, the physiological meaning of GSN's presence in extracellular spaces such as airway surface fluid (ASF), cerebrospinal fluid, lymph and peritoneum has yet to be explored, although it may be assumed that the function of GSN in all those compartments would be similar to plasma GSN's. In one recent study decreased levels of gelsolin in CSF were observed in HIV infected patients who develop HIV-1 associated dementia (HAD) [141] and gelsolin was found at high levels in mesenteric lymph in which a drastic decrease was detected after hemorrhagic shock [65].

\section{E. GSN BINDS ABETA - The Peptide Involved in Alz- heimer's Disease Development}

In addition to CSF and critical care conditions, plasma gelsolin has potential as a treatment in Alzheimer's disease (AD), which is caused by the accumulation and deposition of the 40-42 amino acid peptide amyloid beta (Abeta). Soluble Abeta is present normally both in plasma and in the cerebrospinal fluid and becomes fibrillar and deposits as plaques in the brains of patients with $\mathrm{AD}[142,143]$. Secreted gelsolin binds to Abeta in a concentration-dependent and specific manner. Solid phase binding assays showed two Abeta binding sites on gelsolin that have dissociation constants of 1.38 and $2.55 \mu \mathrm{M}$, and this peptide was found to co-immunoprecipitate with gelsolin from plasma, suggesting that gelsolin-Abeta complexes exist under physiological conditions $[142,143]$. Peripheral delivery of plasmid DNA coding for plasma gelsolin reduces brain amyloid beta in two separate amyloid-depositing transgenic mouse models of AD [144, 145]. These findings suggest that plasma gelsolin might be considered as a treatment for Abeta plaque formation in $\mathrm{AD}$, although the low affinity of binding predicted from the dissociation constant raises concerns about competition from other gelsolin binding partners in vivo. 


\section{SUMMARY}

This review has focused on the functions of plasma gelsolin, specifically underlining the ability of this protein to depolymerize extracellular F-actin and buffer the activity of several inflammatory mediators. These functions are suggestive of gelsolin's ability to prevent the chain of reactions leading to the development of secondary injury in septic animals and raise hope that repletion of plasma gelsolin will offer new treatment options, in parallel to evaluation of blood gelsolin concentration as a prognostic marker.

\section{ABBREVIATIONS}

\begin{tabular}{|c|c|c|}
\hline Ap3A & $=$ & Diadenosine-5', 5"-P1,P3-triphostate \\
\hline BSA & $=$ & Bovine serum albumin \\
\hline CAPs & $=$ & Cationic antibacterial peptides \\
\hline CD14 & $=$ & $\begin{array}{l}\text { A } 55-\mathrm{kD} \text { protein involved in the serum- } \\
\text { dependent response of cells to bacterial } \\
\text { lipopolysaccharide }\end{array}$ \\
\hline CLP & $=$ & Cecal ligation and puncture \\
\hline CSA & $=$ & Cationic steroid antibiotics \\
\hline FAF & $=$ & Familial amyloidosis of the Finnish type \\
\hline $\mathrm{FEV}_{1}$ & $=$ & $\begin{array}{l}\text { The volume exhaled during the first second of } \\
\text { a forced expiratory maneuver }\end{array}$ \\
\hline GSN & $=$ & Gelsolin \\
\hline GSN-c68 & $=$ & $\begin{array}{l}68 \mathrm{kDa} \text { carboxyl-terminal fragment of FAF } \\
\text { gelsolin }\end{array}$ \\
\hline LBP & $=$ & LPS-binding protein \\
\hline LPS & $=$ & Bacteria lipopolysaccharide (endotoxin) \\
\hline LTA & $=$ & Lipotechoic acid \\
\hline LPA & $=$ & Lysophosphatidic acid \\
\hline MMPs & $=$ & Matrix metalloproteinases \\
\hline MD2 & $=$ & $\begin{array}{l}\text { A small protein associated with TLR4 re- } \\
\text { quired for LPS signaling }\end{array}$ \\
\hline $\mathrm{NF}-\kappa \mathrm{B}$ & $=$ & Nuclear factor kappa B \\
\hline PAF & $=$ & Platelet-activating factor \\
\hline PBP10 & $=$ & $\begin{array}{l}\text { Gelsolin-derived rhodamine B-conjugated } \\
\text { peptide (QRLFQVKGRR) }\end{array}$ \\
\hline $\mathrm{PIP}_{2}$ & $=$ & Phosphatidylinositol 4,5-bisphosphate \\
\hline PPI & $=$ & Polyphosphoinositides \\
\hline $\mathrm{PC}$ & $=$ & Phosphatidycholine \\
\hline PS & $=$ & Phosphatidylserine \\
\hline $\mathrm{RBC}$ & $=$ & Red blood cells \\
\hline S1P & $=$ & Sphingosine 1- phosphate \\
\hline TNF- $\alpha$ & $=$ & Tumor necrosis factor alpha \\
\hline TLR & $=$ & Toll-like receptors \\
\hline TRAP & $=$ & Thrombin receptor activating peptide. \\
\hline
\end{tabular}

\section{REFERENCES}

[1] Yin, H.L. and Stossel, T.P. (1979) Nature, 281, 583-586.

[2] Janmey, P.A. and Lind, S.E. (1987) Blood, 70, 524-530.

[3] Lind, S.E., Smith, D.B., Janmey, P.A. and Stossel, T.P. (1988) Am. Rev. Respir. Dis., 138, 429-434.

[4] Yin, H.L., Kwiatkowski, D.J., Mole, J.E. and Cole, F.S. (1984) $J$. Biol. Chem., 259, 5271-5276.

[5] Zapun, A., Grammatyka, S., Deral, G. and Vernet, T. (2000) Biochem. J., 350 (Pt 3), 873-881.

[6] Kwiatkowski, D.J., Stossel, T.P., Orkin, S.H., Mole, J.E., Colten, H.R. and Yin, H.L. (1986) Nature, 323, 455-458.

[7] Kwiatkowski, D.J., Westbrook, C.A., Bruns, G.A. and Morton, C.C. (1988) Am. J. Hum. Genet., 42, 565-575.

[8] Kwiatkowski, D.J., Mehl, R. and Yin, H.L. (1988) J. Cell Biol., 106, 375-384.

[9] Mishra, V.S., Henske, E.P., Kwiatkowski, D.J. and Southwick, F.S (1994) Genomics, 23, 560-565.

[10] Arai, M. and Kwiatkowski, D.J. (1999) Dev. Dyn., 215, 297-307.

[11] Ashish, S., Paine, M.S., Perryman, P.B., Yang, L., Yin, H.L. and Krueger, J.K. (2007) J. Biol. Chem., 282, 25884-25892.

[12] Kothakota, S., Azuma, T., Reinhard, C., Klippel, A., Tang, J., Chu, K., McGarry, T.J., Kirschner, M.W., Koths, K., Kwiatkowski, D.J. and Williams, L.T. (1997) Science, 278, 294-298.

[13] Kamada, S., Kusano, H., Fujita, H., Ohtsu, M., Koya, R.C., Kuzumaki, N. and Tsujimoto, Y. (1998) Proc. Natl. Acad. Sci. USA, 95, 8532-8537.

[14] Wen, D., Corina, K., Chow, E.P., Miller, S., Janmey, P.A. and Pepinsky, R.B. (1996) Biochemistry, 35, 9700-9709.

[15] Burtnick, L.D., Koepf, E.K., Grimes, J., Jones, E.Y., Stuart, D.I., McLaughlin, P.J. and Robinson, R.C. (1997) Cell, 90, 661-670.

[16] Janmey, P.A., Iida, K., Yin, H.L. and Stossel, T.P. (1987) J. Biol. Chem., 262, 12228-12236.

[17] Pope, B., Maciver, S. and Weeds, A. (1995) Biochemistry, 34, $1583-1588$

[18] Rouayrenc, J.F., Fattoum, A., Mejean, C. and Kassab, R. (1986) Biochemistry, 25, 3859-3867.

[19] Barkalow, K., Witke, W., Kwiatkowski, D.J. and Hartwig, J.H. (1996) J. Cell Biol., 134, 389-399.

[20] Sun, H.Q., Yamamoto, M., Mejillano, M. and Yin, H.L. (1999) J. Biol. Chem., 274, 33179-33182.

[21] Coue, M. and Korn, E.D. (1986) J. Biol. Chem., 261, 1588-1593.

[22] McLaughlin, P.J., Gooch, J.T., Mannherz, H.G. and Weeds, A.G. (1993) Nature, 364, 685-692.

[23] Gremm, D. and Wegner, A. (1999) Eur. J. Biochem., 262, 330-334.

[24] Gremm, D. and Wegner, A. (2000) Eur. J. Biochem., 267, 43394345.

[25] Choe, H., Burtnick, L.D., Mejillano, M., Yin, H.L., Robinson, R.C. and Choe, S. (2002) J. Mol. Biol., 324, 691-702.

[26] Narayan, K., Chumnarnsilpa, S., Choe, H., Irobi, E., Urosev, D., Lindberg, U., Schutt, C.E., Burtnick, L.D. and Robinson, R.C. (2003) FEBS Lett., 552, 82-85.

[27] Burtnick, L.D., Urosev, D., Irobi, E., Narayan, K. and Robinson, R.C. (2004) EMBO J., 23, 2713-2722.

[28] Robinson, R.C., Mejillano, M., Le, V.P., Burtnick, L.D., Yin, H.L. and Choe, S. (1999) Science, 286, 1939-1942.

[29] Lamb, J.A., Allen, P.G., Tuan, B.Y. and Janmey, P.A. (1993) $J$. Biol. Chem., 268, 8999-9004.

[30] Lin, K.M.,Wenegieme, E., Lu, P.J., Chen, C.S. and Yin, H.L. (1997) J. Biol. Chem., 272, 20443-20450.

[31] Janmey, P.A. and Stossel, T.P. (1987) Nature, 325, 362-364.

[32] Doi, Y., Hashimoto, T., Yamaguchi, H. and Vertut-Doi, A. (1991) Eur. J. Biochem., 199, 277-283.

[33] Stossel, T.P. (1989) J. Biol. Chem., 264, 18261-18264.

[34] Janmey, P.A. (1994) Annu. Rev. Physiol., 56, 169-191.

[35] Yin, H.L., Iida, K. and Janmey, P.A. (1988) J. Cell Biol., 106, 805812.

[36] Kwiatkowski, D.J., Janmey, P.A. and Yin, H.L. (1989) J. Cell Biol., 108, 1717-1726.

[37] Yu, F.X., Sun, H.Q., Janmey, P.A. and Yin, H.L. (1992) J. Biol. Chem., 267, 14616-14621.

[38] Janmey, P.A., Lamb, J., Allen, P.G. and Matsudaira, P.T. (1992) J. Biol. Chem., 267, 11818-11823.

[39] Hartwig, J.H., Bokoch, G.M., Carpenter, C.L., Janmey, P.A., Taylor, L.A., Toker, A. and Stossel, T.P. (1995) Cell, 82, 643-653. 
[40] Bucki, R., Janmey, P.A., Vegners, R., Giraud, F. and Sulpice, J.C. (2001) Biochemistry, 40, 15752-15761.

[41] Meerschaert, K., De Corte, V., De Ville, Y., Vandekerckhove, J. and Gettemans, J. (1998) EMBO J., 17, 5923-5932.

[42] Fueller, M., Wang, D.A., Tigyi, G. and Siess, W. (2003) Cell Signal., 15, 367-375.

[43] Goetzl, E.J., Lee, H., Azuma, T., Stossel, T.P., Turck, C.W. and Karliner, J.S. (2000) J. Biol. Chem., 275, 14573-14578.

[44] Becker, P.M., Kazi, A.A., Wadgaonkar, R., Pearse, D.B., Kwiatkowski, D. and Garcia, J.G. (2003) Am. J. Respir. Cell Mol. Biol., 28, 478-484.

[45] Li, Z., Mintzer, E. and Bittman, R. (2004) Chem. Phys. Lipids, 130, 197-201

[46] Liepina, I., Czaplewski, C., Janmey, P. and Liwo, A. (2003) Biopolymers, $71,49-70$

[47] Flanagan, L.A., Cunningham, C.C., Chen, J., Prestwich, G.D., Kosik, K.S. and Janmey, P.A. (1997) Biophys. J., 73, 1440-1447.

[48] Tuominen, E.K., Holopainen, J.M., Chen, J., Prestwich, G.D., Bachiller, P.R., Kinnunen, P.K. and Janmey, P.A. (1999) Eur. J. Biochem., 263, 85-92.

[49] Bucki, R., Pastore, J.J., Randhawa, P., Vegners, R., Weiner, D.J. and Janmey, P.A. (2004) Antimicrob. Agents Chemother., 48, 1526-1533.

[50] Bucki, R., Georges, P.C., Espinassous, Q., Funaki, M., Pastore, J.J., Chaby, R. and Janmey, P.A. (2005) Biochemistry, 44, 9590-9597.

[51] Bucki, R. and Janmey, P.A. (2006) Antimicrob. Agents Chemother., 50, 2932-2940.

[52] Lee, P.S., Waxman, A.B., Cotich, K.L., Chung, S.W., Perrella, M.A. and Stossel, T.P. (2007) Crit. Care Med., 35, 849-855.

[53] Guha, M. and Mackman, N. (2001) Cell Signal., 13, 85-94.

[54] Bucki, R. and Pastore, J.J. (2006) Eur. J. Haematol., 76, 510-515.

[55] Coade, S.B. and Pearson, J.D. (1989) Circ. Res., 65, 531-537.

[56] Bours, M.J., Swennen, E.L., Di Virgilio, F., Cronstein, B.N. and Dagnelie, P.C. (2006) Pharmacol. Ther., 112, 358-404.

[57] Kaneider, N.C., Mosheimer, B., Reinisch, N., Patsch, J.R. and Wiedermann, C.J. (2004) Thromb. Res., 114, 185-194.

[58] Kambe, H., Ito, H., Kimura, Y., Okochi, T., Yamamoto, H., Hashimoto, T. and Tagawa, K. (1992) J. Biochem. (Tokyo), 111, 722725 .

[59] Harris, H.E. (1985) FEBS Lett., 190, 81-83.

[60] Urosev, D., Ma, Q., Tan, A.L., Robinson, R.C. and Burtnick, L.D. (2006) J. Mol. Biol., 357, 765-772.

[61] Kwiatkowski, D.J., Mehl, R., Izumo, S., Nadal-Ginard, B. and Yin, H.L. (1988) J. Biol. Chem., 263, 8239-8243.

[62] Paunio, T., Kangas, H., Kiuru, S., Palo, J., Peltonen, L. and Syvanen, A.C. (1997) FEBS Lett., 406, 49-55.

[63] Lind, S.E., Smith, D.B., Janmey, P.A. and Stossel, T.P. (1986) J. Clin. Invest., 78, 736-742.

[64] Candiano, G., Bruschi, M., Pedemonte, N., Caci, E., Liberatori, S., Bini, L., Pellegrini, C., Vigano, M., O'Connor, B.J., Lee, T.H., Galietta, L.J. and Zegarra-Moran, O. (2005) Am. J. Respir. Crit. Care Med., 172, 1090-1096.

[65] Jordan, J.R., Moore, E.E., Damle, S.S., Eckels, P., Johnson, J.L., Roach, J.P., Redzic, J.S., Hansen, K.C. and Banerjee, A. (2007) J. Surg. Res., 143, 130-135.

[66] Yuan, X. and Desiderio, D.M. (2003) J. Proteome Res., 2, 476-487.

[67] Paunio, T., Kangas, H., Heinonen, O., Buc-Caron, M.H., Robert, J.J., Kaasinen, S., Julkunen, I., Mallet, J. and Peltonen, L. (1998) J. Biol. Chem., 273, 16319-16324.

[68] Fock, U., Jockusch, B.M., Schubert, W.D. and Hinssen, H. (2005) Biochem. J., 385, 659-665.

[69] Lee, P.S. and Waxman, A. (2006) Am. J. Respir. Crit. Care Med., $173,685-689$.

[70] Witke, W., Sharpe, A.H., Hartwig, J.H., Azuma, T., Stossel, T.P. and Kwiatkowski, D.J. (1995) Cell, 81, 41-51.

[71] Lu, M., Witke, W., Kwiatkowski, D.J. and Kosik, K.S. (1997) J. Cell. Biol., 138, 1279-1287.

[72] Endres, M., Fink, K., Zhu, J., Stagliano, N.E., Bondada, V., Geddes, J.W., Azuma, T., Mattson, M. P., Kwiatkowski, D.J. and Moskowitz, M.A. (1999) J. Clin. Invest., 103, 347-354.

[73] Kwiatkowski, D.J. (1999) Curr. Opin. Cell Biol., 11, 103-108.

[74] Azuma, T., Witke, W., Stossel, T.P., Hartwig, J.H. and Kwiatkowski, D.J. (1998) EMBO J., 17, 1362-1370.

[75] Serrander, L., Skarman, P., Rasmussen, B., Witke, W., Lew, D.P., Krause, K.H., Stendahl, O. and Nusse, O. (2000) J. Immunol., 165, 2451-2457.
[76] Witke, W., Li, W., Kwiatkowski, D.J. and Southwick, F.S. (2001) J. Cell Biol., 154, 775-784.

[77] Chan, M.W., El Sayegh, T.Y., Arora, P.D., Laschinger, C.A., Overall, C.M., Morrison, C. and McCulloch, C.A. (2004) J. Biol. Chem., 279, 41047-41057.

[78] Harris, H.E. and Weeds, A.G. (1978) FEBS Lett., 90, 84-88.

[79] Pollard, T.D. and Cooper, J.A. (1986) Аnnu. Rev. Biochem., 55, 987-1035.

[80] Lee, W.M. and Galbraith, R.M. (1992) N. Engl. J. Med., 326, 13351341

[81] Haddad, J.G., Harper, K.D., Guoth, M., Pietra, G.G. and Sanger, J.W. (1990) Proc. Natl. Acad. Sci. USA, 87, 1381-1385.

[82] Erukhimov, J.A., Tang, Z.L., Johnson, B.A., Donahoe, M.P., Razzack, J.A., Gibson, K.F., Lee, W.M., Wasserloos, K.J., Watkins, S.A. and Pitt, B.R. (2000) Am. J. Respir. Crit. Care Med., 162, 288-294.

[83] Basaraba, R.J., Byerly, A.N., Stewart, G.C., Mosier, D.A., Fenwick, B.W., Chengappa, M.M. and Laegreid, W.W. (1998) Microbiology, 144 ( Pt 7), 1845-1852

[84] Lind, S.E. and Smith, C.J. (1991) J. Biol. Chem., 266, 5273-5278

[85] Vasconcellos, C.A. and Lind, S.E. (1993) Blood, 82, 3648-3657.

[86] Herrmannsdoerfer, A.J., Heeb, G.T., Feustel, P.J., Estes, J.E., Keenan, C.J., Minnear, F.L., Selden, L., Giunta, C., Flor, J.R. and Blumenstock, F.A. (1993) Am. J. Physiol., 265, G1071-81.

[87] Smith, D.B., Janmey, P.A., Sherwood, J.A., Howard, R.J. and Lind, S.E. (1988) Blood, 72, 214-218.

[88] Smith, D.B., Janmey, P.A. and Lind, S.E. (1988) Am. J. Pathol., 130, 261-267.

[89] DiNubile, M.J. (2007) Am. J. Physiol. Cell Physiol., 292, C12401242.

[90] Bini, A., Itoh, Y., Kudryk, B.J. and Nagase, H. (1996) Biochemistry, 35, 13056-13063.

[91] Bini, A., Wu, D., Schnuer, J. and Kudryk, B.J. (1999) Biochemistry, 38, 13928-13936.

[92] Ito, A., Mukaiyama, A., Itoh, Y., Nagase, H., Thogersen, I.B., Enghild, J.J., Sasaguri, Y. and Mori, Y. (1996) J. Biol. Chem., 271, 14657-14660.

[93] Hwang, I.K., Park, S.M., Kim, S.Y. and Lee, S.T. (2004) Biochim. Biophys. Acta, 1702, 79-87.

[94] Park, S.M., Hwang, I.K., Kim, S.Y., Lee, S.J., Park, K.S. and Lee, S.T. (2006) Proteomics, 6, 1192-1199.

[95] Koya, R.C., Fujita, H., Shimizu, S., Ohtsu, M., Takimoto, M., Tsujimoto, Y. and Kuzumaki, N. (2000) J. Biol. Chem., 275 , 15343-15349.

[96] Geng, Y.J., Azuma, T., Tang, J.X., Hartwig, J.H., Muszynski, M., Wu, Q., Libby, P. and Kwiatkowski, D.J. (1998) Eur. J. Cell Biol., 77, 294-302

[97] Kiuru, S. (1992) Acta Neurol. Scand., 86, 346-353.

[98] Maury, C.P., Sletten, K., Totty, N., Kangas, H. and Liljestrom, M. (1997) Lab. Invest., 77, 299-304.

[99] Page, L.J., Suk, J.Y., Huff, M.E., Lim, H.J., Venable, J., Yates, J., Kelly, J.W. and Balch, W.E. (2005) EMBO J., 24, 4124-4132.

[100] Ware, L.B. and Matthay, M.A. (2000) N. Engl. J. Med., 342, 13341349.

[101] Suhler, E., Lin, W., Yin, H.L. and Lee, W.M. (1997) Crit. Care Med., 25, 594-598

[102] Mounzer, K.C., Moncure, M., Smith, Y.R. and DiNubile, M.J. (1999) Am. J. Respir. Crit. Care Med., 160, 1673-1681.

[103] Dahl, B., Schiodt, F.V., Ott, P., Gvozdenovic, R., Yin, H.L. and Lee, W.M. (1999) Shock, 12, 102-104.

[104] Lee, P.S., Drager, L.R., Stossel, T.P., Moore, F.D. and Rogers, S.O. (2006) Ann. Surg., 243, 399-403.

[105] DiNubile, M.J., Stossel, T.P., Ljunghusen, O.C., Ferrara, J.L. and Antin, J.H. (2002) Blood, 100, 4367-4371

[106] Cano, M.L., Cassimeris, L., Fechheimer, M. and Zigmond, S.H (1992) J. Cell Biol., 116, 1123-34.

[107] Redmond, T. and Zigmond, S.H. (1993) Cell Motil. Cytoskeleton, 26, 7-18.

[108] Zigmond, S.H. (1993) Cell Motil. Cytoskeleton, 25, 309-316.

[109] Meier, U., Gressner, O., Lammert, F. and Gressner, A.M. (2006) Clin. Chem., 52, 1247-1253.

[110] Paunio, T., Kiuru, S., Karonen, S.L., Palo, J. and Peltonen, L. (1994) Int. J. Exp. Clin. Invest., 1, 80-89.

[111] Lofberg, M., Paunio, T., Tahtela, R., Kiuru, S. and Somer, H. (1998) J. Neurol. Sci., 157, 187-190. 
[112] Janmey, P.A., Lind, S.E., Yin, H.L. and Stossel, T.P. (1985) Biochim. Biophys. Acta, 841, 151-159.

[113] Vasconcellos, C.A., Allen, P.G., Wohl, M.E., Drazen, J.M., Janmey, P.A. and Stossel, T.P. (1994) Science, 263, 969-971.

[114] Tang, J.X., Wen, Q., Bennett, A., Kim, B., Sheils, C.A., Bucki, R. and Janmey, P.A. (2005) Am. J. Physiol. Lung Cell. Mol. Physiol., 289, L599-605.

[115] Whitby, P.W., Dick, H.L., Campbell, P.W., Tullis, D.E., Matlow, A., Stull, T.L. (1998) J. Clin. Microbiol., 36, 1642-1645

[116] Walker, T.S., Tomlin, K.L., Worthen, G.S., Poch, K.R., Lieber, J.G., Saavedra, M.T., Fessler, M.B., Malcolm, K.C., Vasil, M.L. and Nick, J.A. (2005) Infect. Immun., 73, 3693-3701.

[117] Hodson, M. (1995) Arch. Pediatr., 2, 679-681.

[118] Hodson, M.E. (1995) Respiration, 62 (Suppl 1), 29-32.

[119] Weiner, D.J., Bucki, R. and Janmey, P.A. (2003) Am. J. Respir. Cell Mol. Biol., 28, 738-745.

[120] Bucki, R., Byfield, F.J. and Janmey, P.A. (2007) Eur. Respir. J., $29,624-632$

[121] Bucki, R., Sostarecz, A.G., Byfield, F.J., Savage, P.B. and Janmey, P.A. (2007) J. Antimicrob. Chemother., 60, 535-545.

[122] Ernst, R.K., Yi, E.C., Guo, L., Lim, K.B., Burns, J.L., Hackett, M. and Miller, S.I. (1999) Science, 286, 1561-1565.

[123] Gibson, R.L., Burns, J.L. and Ramsey, B.W. (2003) Am. J. Respir. Crit. Care Med., 168, 918-951

[124] Bucki, R., Levental, I. and Janmey, P.A. (2007) Anti. Infect. Agents Med. Chem., 6, 175-184.

[125] Christofidou-Solomidou, M., Scherpereel, A., Solomides, C.C., Muzykantov, V.R., Machtay, M., Albelda, S.M. and DiNubile, M.J. (2002) Lung, 180, 91-104.

[126] Christofidou-Solomidou, M., Scherpereel, A., Solomides, C.C., Christie, J.D., Stossel, T.P., Goelz, S. and DiNubile, M.J. (2002) J. Investig. Med. 50, 54-60.

[127] Rothenbach, P.A., Dahl, B., Schwartz, J.J., O'Keefe, G.E., Yamamoto, M., Lee, W.M., Horton, J.W., Yin, H.L. and Turnage, R.H. (2004) J. Appl. Physiol., 96, 25-31.
[128] Messaris, E. (2007) Crit. Care Med., 35, 970-971.

[129] Osborn, T.M., Dahlgren, C., Hartwig, J.H. and Stossel, T.P. (2007) Am. J. Physiol. Cell Physiol., 292, C1323-330.

[130] Mintzer, E., Sargsyan, H. and Bittman, R. (2006) Biochim. Biophys. Acta, 1758, 85-89.

[131] Vartanian, A.A. (2003) Ital. J. Biochem., 52, 9-16.

[132] Lavery, G.G. and Lowry, K.G. (2004) Curr. Opin. Anaesthesiol., 17, 151-157.

[133] Rodrigo, R., Trujillo, S. and Bosco, C. (2006) Exp. Biol. Med. (Maywood), 231, 1430-1438.

[134] Matsumoto, K., Taki, F., Kondoh, Y., Taniguchi, H. and Takagi, K. (1992) Clin. Exp. Pharmacol. Physiol., 19, 509-515

[135] Zimmerman, G.A., McIntyre, T.M., Prescott, S.M. and Stafforini, D.M. (2002) Crit. Care Med.,30, S294-301.

[136] Karasawa, K. (2006) Biochim. Biophys. Acta, 1761, 1359-1372.

[137] Nagi-Miura, N., Shingo, Y., Kurihara, K., Adachi, Y., Suzuki, K. and Ohno, N. (2007) Biol. Pharm. Bull., 30, 1354-1357.

[138] Kume, H., Ito, S., Ito, Y. and Yamaki, K. (2001) Am. J. Respir. Cell Mol. Biol., 25, 291-298.

[139] Kim, Y.J., Kim, K.P., Han, S.K., Munoz, N.M., Zhu, X., Sano, H., Leff, A.R. and Cho, W. (2002) J. Biol. Chem., 277, 36479-36488.

[140] Legradi, A., Chitu, V., Szukacsov, V., Fajka-Boja, R., Szekely Szucs, K. and Monostori, E. (2004) Immunol. Lett., 91, 17-21.

[141] Rozek, W., Ricardo-Dukelow, M., Holloway, S., Gendelman, H.E., Wojna, V., Melendez, L.M. and Ciborowski, P. (2007) J. Proteome Res., 6, 4189-4199.

[142] Chauhan, V.P., Ray, I., Chauhan, A. and Wisniewski, H.M. (1999) Biochem. Biophys. Res. Commun., 258, 241-246.

[143] Ray, I., Chauhan, A., Wegiel, J. and Chauhan, V.P. (2000) Brain Res., 853, 344-351.

[144] Matsuoka, Y., Saito, M., LaFrancois, J., Gaynor, K., Olm, V., Wang, L., Casey, E., Lu, Y., Shiratori, C., Lemere, C. and Duff, K. (2003) J. Neurosci., 23, 29-33.

[145] Hirko, A.C., Meyer, E.M., King, M.A. and Hughes, J.A. (2007) Mol. Ther., 15, 1623-1629. 